\title{
Gammaglobulin Treatment in an Unusual Meningococcal Case
}

\author{
Laura Garriga-Grimau • Vanessa Laveglia
}

Received: 5 June 2013 / Accepted: 14 August 2013 /Published online: 21 September 2013

(C) Dr. K C Chaudhuri Foundation 2013

To the Editor: Prolonged fever is a possible complication of meningococcal meningitis, appearing in approximately $10 \%$ of cases. Defined as fever lasting from four to ten days after the symptoms of meningitis begin, it can be classified as persistent, secondary or recurrent [1].

In the persistent type, the fever never disappears, and intracranial causes such as brain abscesses, subdural empyema, and vasculitis must be ruled out [1]. The secondary fever re-appears atleast $24 \mathrm{~h}$ after being afebrile. Extracranial causes should be suspected, including viral and bacterial infections $[2,3]$. Finally, with the recurrent fever, a parameningeal focus of infection and congenital defects should be investigated [1].

We report an 11-mo-old male infant with meningococcal meningitis septicemia, who remained afebrile between 24 and $72 \mathrm{~h}$ after starting the antibiotic therapy. Fever re-appeared on the fourth day of antibiotic treatment, associated with palpable nodules on his left arm. Four days later, despite non-steroidal anti-inflammatory drugs (NSAIDs) being administered, vasculitis by immune complexes was suspected, and oral steroid treatment with prednisolone was initiated with doses of $2 \mathrm{mg} /$ $\mathrm{kg} / \mathrm{d}$. He remained afebrile afterwards and was discharged two days later, receiving antibiotic treatment and oral steroids for a week.

Fever re-appeared $24 \mathrm{~h}$ after steroid treatment was completed. Palpable nodular elements persisted together with the appearance of new ones, and arthralgia and a systolic murmur were detected. We restarted $2 \mathrm{mg} / \mathrm{kg} / \mathrm{d}$ prednisolone dose with subsequent tapering to $0.3 \mathrm{mg} / \mathrm{kg} / \mathrm{d}$, with new fever recurrence after it was suspended.

L. Garriga-Grimau $(\bowtie) \cdot$ V. Laveglia

Department of Pediatrics, Hospital del Mar, Parc de Salut Mar,

Universitat Autònoma Barcelona, Passeig Marítim de la Barceloneta

25-29, 08003 Barcelona, Spain

e-mail: 60490@parcdesalutmar.cat
Laboratory studies showed declining levels of C-reactive protein and the erythrocyte sedimentation rate, rising levels of complement factors, negative antinuclear antibody and rheumatoid factor. An echocardiography and urinalysis were normal.

The immune complex vasculitis-arthritis was controlled with steroid treatment but was not resolved yet. Two doses of $2 \mathrm{~g} / \mathrm{kg} / \mathrm{d}$ of intravenous gammaglobulin were needed, after which the fever and arthralgia disappeared.

The presence of palpable nodules, arthralgia and increased acute phase reactants lead to the diagnosis of vasculitis-athritis by immune complexes $[4,5]$. Although there are no protocols involving immunoglobulins for vasculitis management, it has been an effective and extensive treatment over the years in medical practice. Our patient required two doses of gammaglobulin with subsequent complete remission of symptoms.

Acknowledgments Authors would like to appreciate Martínez-Roig A, Consultant Pediatric, Hospital del Mar, Barcelona, Spain, for his guidance and writing assistance.

\section{References}

1. Baquero Artigao F, Vecino López R, del Castillo Martín F. Bacterial Meningitis. Diagnostic and therapeutic protocols of Infectious Diseases. [serial online]. Madrid: Spanish Association of Pediatrics; 2011 [cited 2013 May 29]. Available from: URL http://www.aeped.es/sites/ default/files/documentos/meningitis.pdf.

2. Balagtas RC, Levin S, Nelson KE, Gotoff SP. Secondary and prolonged fevers in bacterial meningitis. J Pediatr. 1970;77:957-64.

3. Daoud AS, Zaki M, al-Saleh QA. Prolonged and secondary fever in childhood bacterial meningitis. Eur J Pediatr. 1989;149:114-6.

4. Saldaña García N, Rumbao Aguirre JM, Ulloa Santamaría E, Abad Lara JA. Immune complex arthritis meningococcal infection. Ann Pediatr (Barc). 2011;74:344-5.

5. Goedvolk CA, Von Rosenstiel IA, Bos AP. Immune complex associated complications in the subacute phase of meningococcal disease: Incidence and literature review. Arch Dis Child. 2003;88:927-30. 